\title{
Providing care to long-term mechanically ventilated patients in Germany - Current situation and needs for action from the perspective of health professionals Die Versorgung langzeitbeatmeter Patienten in Deutschland - Aktuelle Situation und Handlungsbedarfe aus der Sicht von Gesundheitsberufsangehörigen
}

\author{
Yvonne Lehmann, ${ }^{1 *}$ Susanne Stark, ${ }^{1}$ Michael Ewers ${ }^{1}$ \\ ${ }^{1}$ Charité Universitötsmedizin Berlin, Institut für Gesundheits- \\ und Pflegewissenschaft, 13353 Berlin, Germany \\ *yvonne.lehmann@charite.de
}

Received 13 January 2020, accepted 11 May 2020

\begin{abstract}
Background: The number of patients depending on long-term invasive mechanical ventilation (IMV) has been increasing for several years. Anecdotal reports indicate heterogeneous health structures, opaque patient pathways, nontransparent and sometimes questionable practices in individual areas of care, inadequate quality standards and control mechanisms in Germany. However, there is hardly any empirical data on this topic.

Aim: To report findings from a qualitative study conducted as part of a complex research project to assess the appropriateness of care provided to IMV patients in Germany.

Methods: Thirteen semi-structured expert interviews were conducted with 22 health professionals providing care for IMV patients. The data analysis was conducted with MAXQDA according to the framework by Meuser and Nagel.

Results: Interviewees emphasized similar healthcare deficits. They considered health providers to be nontransparent and influenced by secondary interests. Quality of care is reported to be jeopardized by shortage of trained staff. Warranty of self-determination and participatory decision-making is not a matter of fact. Clarifying issues of sustaining life, quality of life and shaping the end of life is often ignored. The professionals are familiar with the patient pathways, allocation processes and responsibilities described in existing guidelines, but criticize the fact that they are not sufficiently binding. Accordingly, patient pathways are frequently individual results of experience-based, informal networking, and often left to chance.

Conclusions: The results point to a considerable need for action to reach an appropriate, integrated, patient-centered level of care for long-term
\end{abstract} IMV patients and ensure its quality.

\begin{abstract}
Hintergrund: Die Zahl der Patienten, die auf die invasive Langzeitbeatmung angewiesen sind, steigt seit Jahren. Anekdotische Berichte deuten auf heterogene Versorgungsstrukturen, undurchsichtige Patientenpfade, intransparente und teilweise fragwürdige Praktiken sowie unzureichende Qualitätsstandards und Kontrollmechanismen in der Versorgung dieser Patienten in Deutschland hin. Fundierte empirische Daten zu diesem Thema liegen jedoch kaum vor.

Ziel: Ergebnisse einer qualitativen Teilstudie aus einem komplexen Versorgungsforschungsprojekt zur Beurteilung der Bedarfsgerechtigkeit der Versorgung langzeitbeatmeter Patienten in Deutschland werden vorgestellt und reflektiert.

Methodik: Es wurden dreizehn halbstrukturierte Experteninterviews mit 22 Angehörigen verschiedener Gesundheitsberufe aus dem Feld der Versorgung langzeitbeatmeter Patienten durchgeführt. Die Interviewtranskripte wurden mittels MAXQDA nach dem Schema von Meuser und Nagel analysiert.

Ergebnisse: Die Befragten betonten ähnliche Defizite in der Gesundheitsversorgung. Sie schilderten die Leistungserbringung mehrfach als intransparent und von sekundären Interessen beeinflusst. Die Qualität der Versorgung wird aus ihrer Sicht besonders durch den Mangel an qualifiziertem medizinischem, pflegerischem und therapeutischem Personal gefährdet. Die Gewährleistung von Selbstbestimmung und partizipativer Entscheidungsfindung stellt sich als keinesfalls selbstverständlich dar. Die Klärung von Fragen der Lebenserhaltung, der Lebensqualität und der Gestaltung des Lebensendes bleibt vielfach unberücksichtigt. Die Befragten sind mit den in den geltenden Leitlinien beschriebenen Patientenwegen, Zuweisungsprozessen und Verantwortlichkeiten vertraut. Sie kritisieren aber, dass diese nicht ausreichend verbindlich sind. In der Folge sind die Wege der Patienten durch das Versorgungssystem häufig das Ergebnis erfahrungsbasierter, informeller Vernetzungsarbeit und zufallsabhängig.

Schlussfolgerungen: Die Ergebnisse weisen auf einen erheblichen Handlungsbedarf hin, um eine bedarfsgerechte, integrierte, patientenzentrierte Versorgung für invasiv langzeitbeatmete Patienten gewährleisten und deren Qualität sichern zu können.
\end{abstract}

\section{Keywords}

invasive mechanical ventilation - long-term care - health professionals - Germany - qualitative research - health services research

\section{Keywords}

invasive Beatmung - Langzeitversorgung - Gesundheitsberufsangehörige - Deutschland - qualitative Studie - Versorgungsforschung 


\section{INTRODUCTION}

The number of patients depending on long-term invasive mechanical ventilation (IMV) has increased in last years (Simonds, 2016; Ambrosino \& Vitacca, 2018). International reports indicate that prevalence rates continue to rise due to demographic and epidemiological changes, advances in diagnostic and supportive technology, improved healthcare delivery and a better understanding of the beneficial effects of IMV on quality of life in some conditions (Rose et al., 2015).

Many IMV patients are seriously ill, have complex medical needs and require specialized multi-professional long-term care, which calls for a high level of coordination and cooperation between all sectors, organizations, and professions involved (Ambrosino \& Vitacca, 2018). Cases in which comprehensive support around the clock is needed are very common. It is estimated that about 20,000 IMV-assisted individuals in Germany receive this type of intensive care in their own home or in supervised flat-sharing communities, most of them on a 24/7 basis (Lehmacher-Dubberke, 2016). Their exact number is unknown due to a lack of a comprehensive database or national registry for the patient group (Stark et al., 2019). Anecdotal reports point to challenges that jeopardize the quality and outcomes of healthcare to IMV patients in Germany, consisting of heterogeneous health structures at a national level, opaque patient pathways through the health system, nontransparent and sometimes questionable practices in single areas of care, inadequate quality standards and control mechanisms (DIGAB, 2017). However, there are hardly any empirical data on these topics.

\section{Background}

Since the ruling of the German Federal Social Court in 1999, every patient with IMV or other life-prolonging technologies with acknowledged complex and extensive healthcare needs has the right to be cared for inhome care settings (i.e., private home, flat-sharing communities) up to 24 hours a day (Bundessozialgericht, 1999). This decision initiated the development and rapid expansion of specialized services for IMV and other technically dependent persons (Advisory Council, 2014). At present, invasive home mechanical ventilation has become a well-established intervention in Germany, and specialized clinical services of acute care hospitals and rehabilitation clinics are complemented by a large variety of specialized community services, starting from resident physicians to (institutional) nursing care services and therapists to providers of medical supplies. The majority of these services operates under private ownership, including the medical-industrial sector (Stark et al., 2016). Furthermore, those providers usually work independently, with cross-sectoral and interprofessional collaboration being uncommon.

The responsibility for ensuring adequate home care for ventilated or other technically dependent patients up to 24 hours a day lies with the providers of nursing care. Each of the approx. 14,000 existing German home nursing services (Destatis, 2018) are generally allowed to provide this type of care. The nursing services provided are based on individual contracts between patients, providers and health insurance companies. Federal quality standards on nursing and other dimensions of specialized healthcare are to date missing. In fact, existing German guideline on "Non-Invasive and Invasive Mechanical Ventilation for the Treatment of Chronic Respiratory Failure" (Windisch et al., 2017) offers non-mandatory guidance for specialized healthcare for the patient group in clinical and community settings, such as for technical issues, organizational structures, follow-up and monitoring of ventilation, qualification criteria or discharge management. However, the guideline remain silent on how to organize and conduct continuing, multiprofessional and cross-sectoral long-term care to address the patients' complex needs and ensure high-quality care. Internationally, healthcare for IMV and other technically dependent persons has also dynamically developed in the last two decades - for example, Sweden (Geisewall et al., 2015), Poland (Nasiłowski et al., 2015), Canada (Povitz et al., 2018), and the United States (Sahetya et al., 2016) - and seems to face similar challenges to appropriate healthcare, such as poor quality of care, inappropriate qualification and expertise, service fragmentation, regional disparities and access barriers. Although little is known about healthcare for IMV patients in different national or regional contexts, international consensus exists that improved access to, efficiency and outcomes of healthcare necessitate continuing, interprofessional and cross-sectoral approaches healthcare (Stark \& Ewers, submitted). German initiatives to implement those principles into everyday care for IMV patients are rare. Current practices rather seem to reflect the existing lack of regulation and guidance to arrange and further develop specialized services adequately.

Against this background, a multi-component mixedmethod health services research project (VELARegio, 2015-2016) was conducted. The study aimed to determine existing health services for long-term IMV patients in a contrastive sample of four urban and rural German regions (Schwerin, Berlin, Hof, Tübingen) and to explore patient pathways throughout the care continuum, the appropriateness of existing health services and processes, challenges, optimization needs and opportunities within those regions. Three work packages were sequentially conducted, summarized and discussed 


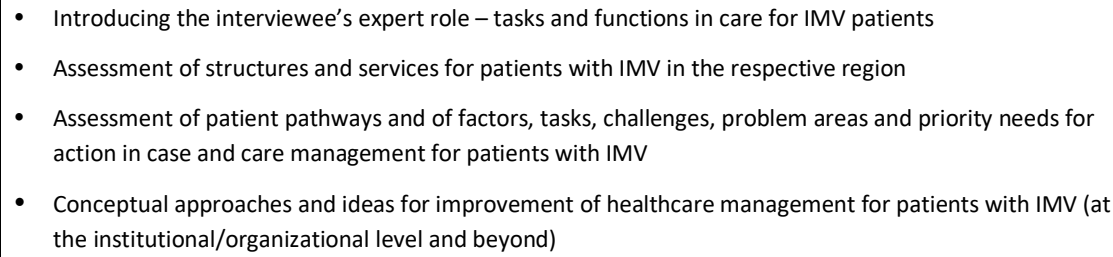

- Conceptual approaches and ideas for improvement of healthcare management for patients with IMV (at the institutional/organizational level and beyond)

Figure 1: Topics of the interview guide.

to develop recommendations for the future organization and management of care for long-term IMV patients in Germany.

\begin{abstract}
Aim
This article presents key findings from one of these work packages. The aim of this part of the overall research project was a dense description of the current situation and needs for action in providing care to long-term mechanically ventilated patients in Germany from the perspective of health professionals. The results should be discussed in light of (inter-)national theoretical discourses on the principles of needs-based health system design, continuity and integration of individual case management. In this way, one of several building blocks for the development of recommendations for the care for long-term IMV patients in Germany should be provided. The research question addressed the current situation of healthcare provision for long-term IMV patients in the four German regions, existing regional similarities and differences from the health professionals' perspective. Furthermore, it was asked, how the pathways the patients take through the health system can be described from the "insiders" perspective and what needs for action exist to improve healthcare for long-term IMV patients.

Further results of the VELA-Regio project have been published as a research report in three comprehensive working papers (Lehmann et al., 2016a, b; Stark et al., 2016) and in the form of a discussion of partial aspects of the overall project with health policy objectives (Ewers \& Lehmann, 2018). The results presented here were not focused on in these past publications.
\end{abstract}

\section{METHODS}

\section{Study design}

An explorative, qualitative research design using expert interviews as described by Meuser and Nagel (2009) was adopted to gain in-depth insights into this largely unexplored field. According to Meuser and Nagel, "experts" are considered to be individuals who are themselves part of or have documented expertise in the field under study and are thus able to provide specific insights (Meuser \& Nagel, 2009). Health professionals were eligible participating as experts in this study if they had an organizational or institutional connection to longterm care of IMV patients or had privileged access to information on IMV patients in or beyond the selected regions, and were experienced (at least one year) in health provision or management for these patients. Particular consideration on differences and variation in professional perspectives should be achieved by including experts with a wide range of responsibilities or institutional and professional affiliation from different sectors and settings in the four selected regions, such as specialized hospitals or resident physicians, senior nurses of intensive nursing care services, case managers in a rehabilitation clinic, and employees of health insurances.

\section{Data collection and analysis}

The research project VELA-Regio followed the rules of good scientific practice, including verbal and written informed consent on the study's purpose, procedures and data protection. The semi-structured expert interviews with four topics (Figure 1) were conducted face-to-face at the interviewees' workplace or via phone between September 2015 and March 2016.

The interviews were digitally audio-recorded and transcribed verbatim, except for one interview, which was documented by an interview protocol upon request of the interviewees. The analysis of all interviews was carried out using MAXQDA software and based on the step-by-step framework of Meuser and Nagel (2009) in the following sequence: The transcripts were initially read and paraphrased to gain a thematic overview. Text segments of each interview that built units of meaning were labelled with inductive codes. Subsequently, a thematic comparison, clustering, abstraction and thematic conceptualization across interviews was conducted. Codes with similar meaning were structured, condensed and abstracted to preliminary themes and (sub-)categories, followed by further condensation, highlighting thematic similarities and differences. Finally, the results were discussed against the background of theoretical discourses on the principles of needs-based health system design, 
Table 1: Interview Data.

\begin{tabular}{|c|c|c|c|c|}
\hline Id & Area of healthcare & $\begin{array}{c}\text { Number of } \\
\text { participants (N) }\end{array}$ & $\begin{array}{l}\text { Qualification and function of } \\
\text { participants }\end{array}$ & $\begin{array}{l}\text { Interview type, duration and } \\
\text { documentation }\end{array}$ \\
\hline 1 & Weaning and ventilation center & 1 & physician (senior) & face-to-face, $90 \mathrm{~min}$, audio-record \\
\hline 2 & Weaning and ventilation center & 2 & $\begin{array}{c}\text { physician (senior), nurse (discharge } \\
\text { management) }\end{array}$ & face-to-face, $70 \mathrm{~min}$, paper/pencil \\
\hline 3 & Specialized nursing home & 2 & $\begin{array}{l}\text { nurse (management), physician } \\
\text { (management) }\end{array}$ & face-to-face, $95 \mathrm{~min}$, audio-record \\
\hline 4 & Specialized nursing home & 1 & nurse (director of nursing care) & phone, $65 \mathrm{~min}$, audio-record \\
\hline 5 & $\begin{array}{l}\text { Nursing home with specialized } \\
\text { intensive care ward }\end{array}$ & 1 & nurse (director of nursing care) & face-to-face, $65 \mathrm{~min}$, audio-record \\
\hline 6 & Health insurance & 2 & nurse (case management) & Face-to-face, $90 \mathrm{~min}$, audio-record \\
\hline 7 & $\begin{array}{c}\text { Acute care hospital with weaning } \\
\text { unit }\end{array}$ & 5 & $\begin{array}{c}\text { physician (senior), nurse (respiratory } \\
\text { therapist, } n=2 \text { ), nurse (discharge } \\
\text { management, } n=2 \text { ) }\end{array}$ & face-to-face, $60 \mathrm{~min}$, audio-record \\
\hline 8 & Intensive nursing care service & 1 & nurse (management) & face-to-face, $50 \mathrm{~min}$, audio-record \\
\hline 9 & Intensive nursing care service & 1 & economist (director) & face-to-face, $60 \mathrm{~min}$, audio-record \\
\hline 10 & $\begin{array}{l}\text { Specialized resident physician } \\
\text { practice }\end{array}$ & 2 & $\begin{array}{c}\text { physician, nurse (respiratory } \\
\text { therapist) }\end{array}$ & face-to-face, $210 \mathrm{~min}$, audio-record \\
\hline 11 & $\begin{array}{l}\text { Specialized resident physician } \\
\text { practice }\end{array}$ & 1 & physician & phone, $38 \mathrm{~min}$, audio-record \\
\hline 12 & \begin{tabular}{|c|}
$\begin{array}{c}\text { Medical service of the statutory } \\
\text { health insurance }\end{array}$ \\
\end{tabular} & 1 & $\begin{array}{c}\text { nurse (assessment of care } \\
\text { dependency, quality assurance) }\end{array}$ & face-to-face, $85 \mathrm{~min}$, audio-record \\
\hline 13 & Neurological early rehabilitation & 2 & physician (senior), nurse (ward nurse) & face-to-face, $80 \mathrm{~min}$, audio-record \\
\hline
\end{tabular}

continuity and integration of individual case management and overall care.

To ensure reliability of the research process, the analysis was performed by two researchers (YL, ST) with a nursing science and public health background. The results were regularly discussed and reflected by the members of the research team throughout the analysis process. Differing interpretations were discussed by all authors (YL, ST, $\mathrm{ME}$ ) until a consensus was reached.

\section{RESULTS}

Although a high reservation to participate in the interviews was observed, 13 interviews were conducted with 22 experts ( 8 women, 14 men) from across the entire healthcare spectrum for long-term IMV patients. The institutional and professional background of the interviewees, the number of participants in each interview and information about the data collection are documented in Table 1. The interviews took between 40 and $210 \mathrm{~min}$ (mean: $81 \mathrm{~min}$ ). The number of participants per interview varied between 1 and 5 persons and their professional experiences ranged from about 1.5 to over 20 years.

Four main categories with five sub-categories emerged from the analysis (Figure 2). The categories reflect the perspectives of interviewees regarding the patient groups with long-term IMV, the specialized structures and services within the health system, on the patient pathways through the system, and finally, their estimates on challenges and needs for action. Due to their expertise and, in some cases, their affiliation with associations and committees, several respondents were able to provide information beyond the specific regional situation. This explains why the results often reflect a universal, trans-regional manner.

\section{Small heterogeneous patient group(s) with different needs}

The interviewees described the group of patients with IMV as relatively small but extremely heterogeneous. They identify two main patient subgroups: (1) patients with elective long-term IMV due to conditions leading to progressive respiratory failure (e.g., neuromuscular or airway diseases), and (2) patients requiring long-term IMV after an episode of acute respiratory and weaning failure (also see Rose et al., 2015). Within these two main groups, heterogeneity accompanied with differing needs also results from patients' age (ranging from infants to the very old), their various main and secondary diagnoses (e.g., lung diseases, neuromuscular diseases, conditions after stroke or trauma), and the techniques and types of ventilation. Additionally, patients' social and everyday life circumstances vary considerably.

Depending on these heterogeneous conditions, the healthcare needs IMV patients present vary widely. While some get along with little professional help, other patients may benefit from ongoing weaning attempts and intensive rehabilitation following acute illness episodes and a prolonged period of convalescence. Others depend on palliative care at the end of life due to old age, advanced 


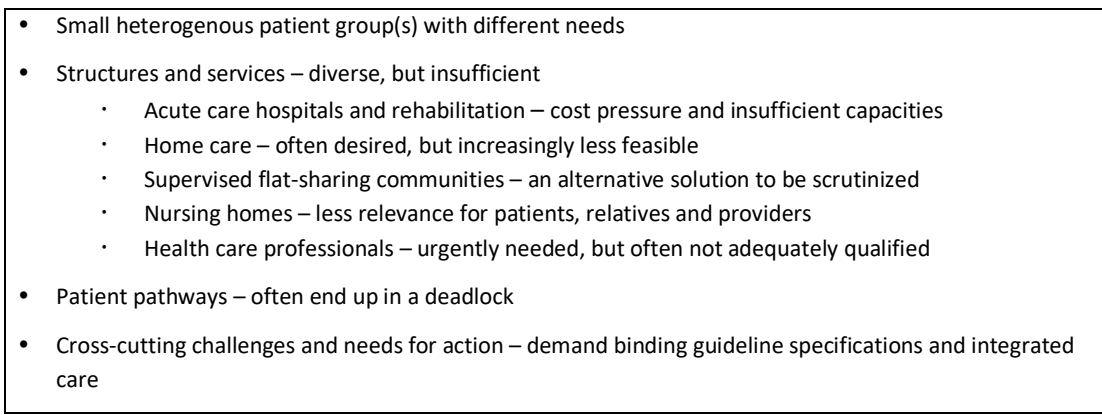

Figure 2: Categories and sub-categories of findings.

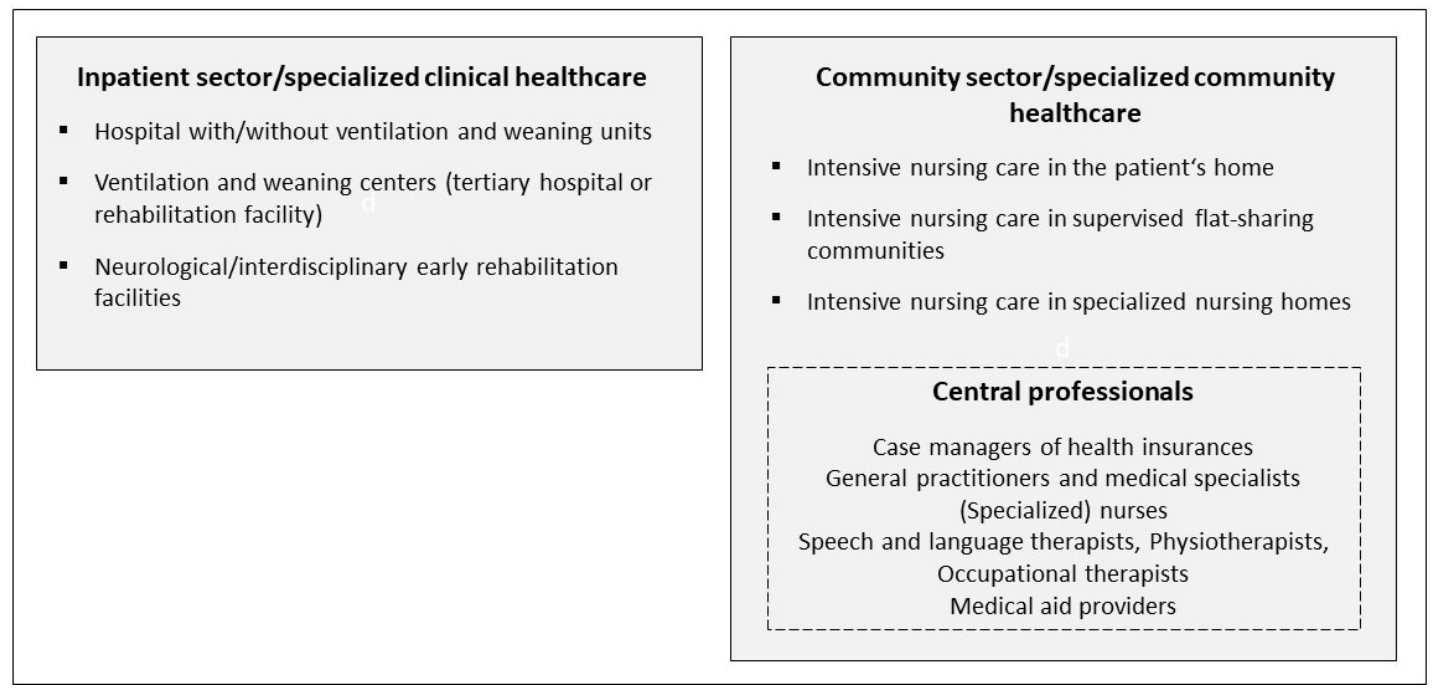

Figure 3: Health structures for ventilated patients from the interviewees' perspective (adapted from Lehmann et al., 2016b).

illness, and a generally very fragile health state. Besides ventilation, additional technical dependency (such as artificial nutrition, dialysis or cardiac support systems) is increasingly common and needs to be considered. According to the interviewees' experience, healthcare strategies and services need to be carefully adapted to these differing needs.

\section{Structures and services - diverse but insufficient}

The experts were asked to assess the structures and facilities of (specialized) healthcare for long-term IMV patients in their regions to subsequently understand their statements and interpretations regarding the patient pathways and the perceived health system issues. Their perspectives on current structures, relevant institutions and professions, are shown in Figure 3. Although the interviewees initially state that existing structures contribute to ensuring healthcare for long-term IMVpatients within the various regions and seem to have more or less arranged with the current local services, their further descriptions draw increasingly differentiated pictures of the regional structures with apparent deficits.

\section{Acute care hospitals and rehabilitation - cost pressure and insufficient capacities}

The interviewees describe the treatment capacity for IMV patients in acute care hospitals and rehabilitation clinics as ranging between very limited to considerably deficient.

"The weaning unit could be three, four times that big, I think, and would still be crowded." (Int. 1)

The main problem appears to be the lacking capacities in intensive care and specialized respiratory/weaning units that provide ventilation weaning expertise or, if necessary, offer continuous support throughout long-term IMV care, as recommended by the current German Guideline on Home Mechanical Ventilation (Windisch et al., 2017). 
Since the demand for these services dramatically exceeds the existing capacities, inevitable patient shifting effects emerge, the experts state. In their perception, these effects are reinforced by the German Diagnosis Related Groups (G-DRG) hospital reimbursement system, which, for economic reasons, aims for the fastest possible hospital discharge, even for seriously ill patients.

\section{Home care - often desired, but increasingly less feasible}

According to the consulted experts, most IMV patients and their relatives prefer to be cared for in their own home. Besides higher satisfaction and quality of life, this preference shall result from the currently low copayments for in-home care compared to other care settings. However, the interviewees identify a significant discrepancy between the high demand for home care and a limited availability of services. Although specialized services enormously expanded in recent decades, this development did not proceed as uniform and extensive as needed, but somewhat random and poorly regulated. The respondents believe that despite the rapid expansion of services, the demand cannot be met. They stress a current lack of specialized services, especially in rural regions with poor infrastructure. Thus, access to home care may not always be guaranteed. As the main reason for this, the experts identify an increasing shortage of qualified nurses and concurrent regulations that oblige nursing care services offering one-on-one intensive home care to ensure that a team of at least five - often more - nurses is available 24/7 for each patient.

The interviewees identify even further barriers that should be carefully taken into account when reflecting on appropriate care settings: Structural unsuitability of private homes for technology-intensive care may pose significant safety risks to patients, relatives and nursing staff. The de-intimisation of the private living environment due to the constant presence of nurses may raise conflicts between family members, tensions between relatives and nursing staff, or a lack of social contacts and loneliness among patients, who are mostly socially isolated. All these aspects, particularly the lack of qualified nursing staff, thwart the development of appropriate structures and services for individual home care. Instead, the experts illustrate, a gentle pressure on nursing care services tends to redirect IMV patients to supervised flat-sharing communities, as the following statement shows:

"It is tried to accommodate the patients together in supervised flat-sharing communities. This is because you can't maintain individual home nursing, due to the staffing situation. There is simply no qualified staff left on [sic] the market." (Int. 5)
Interviewees furthermore emphasize that these increasing refusals on one-on-one care arrangements can lead to inadequate temporal patient transitions to other institutions, considerable burdens, disappointments and safety risks for all stakeholders, especially in cases of high pressure to discharge from acute care or rehabilitation facilities.

\section{Supervised flat-sharing communities - an alternative solution to be scrutinized}

In recent years, supervised flat-sharing communities have been increasingly established as an alternative to individual home care for IMV patients. According to the interviewees, they offer the significant advantage of simultaneously caring for several IMV patients and, as a result, lower logistical and personnel costs compared to one-on-one home care. But they point out nuanced differences of flat-sharing services: While some services are specifically prepared or newly built for the purpose of intensive care for IMV patients, others are not barrierfree and unsuitable in various dimension. The latter may impede social participation of the residents or pose hygiene, accident and fire hazards due to inadequate structural conditions:

"It's difficult when there are stairs. It just doesn't work with a wheelchair. It's not possible to take the tram to the city center or something like that [...]. You get carried in there [the flat-sharing community, author's note] once, and that's it." (Int. 5)

Furthermore, a supervised flat-sharing community could be a three- or four-room apartment with shared rooms, where residents and their relatives come together and spend their everyday lives in a homely, private atmosphere. But the experts also illustrate experiences of significantly larger apartments with more than the regulatory recommended standard of a maximum of 12 residents and a hospital-style without any individual character. Instead, these flats often tend to be externally organized institutions that operate at the confluence of nursing, medical or medical-industrial interests. Only a few services are perceived to correspond to what is thought of as self-determined communal living and to the common term "flat-sharing community". This is mainly attributed to the serious illness of patients, accompanied by limited autonomy.

Consequently, the respondents criticize the fact that flatsharing communities are largely operated in a poorly regulated context. Neither existing high-quality standards of health and nursing care nor external quality control regulations for nursing homes can be applied, as they are legally considered as private homes. 
"These communities are nothing more than a deceptive package. Here, you can evade the regular external inspections by nursing home regulatory authorities and the requirements of a nursing home." (Int. 3)

The missing regulations, experts state, cover considerable hazards to patients. They emphasize that these services are often not representing an innovative type of homecare but rather "hidden" nursing homes, which are very popular among the mostly market and profit-oriented nursing care providers, mainly due to their lower (staff) costs and high-profit prospects. Thus, the respondents perceive the ongoing increase of flat-sharing communities critically, but also judged to be difficult to stop, since these and other new types of assistance for people in need of longterm care enjoy strong political support as alternatives to nursing homes.

\section{Nursing homes - less relevant for patients, relatives and providers}

From the interviewees' perspective, nursing homes do not play an essential role in healthcare for long-term IMV patients in Germany. They describe several underlying reasons: Nursing homes with an exclusive focus on this patient population are rare. Their catchment areas are usually large, and they are therefore hard to reach for relatives. Additionally, experts believe that patients are generally reluctant to move to a nursing home, which is often considered to be the last stage in life. By contrast, supervised flat-sharing communities seem to have a significantly more positive image - irrespective of the quality of life and care in this setting. However, the main reasons for the lower utilization of nursing homes considered by the interviewees are the financial incentive systems and their steering effects: residential long-term care costs for patients requiring intensive care around the clock are not fully reimbursed by the health and long-term care insurance funds. Attempts to shift uncovered costs to patients or their relatives result in very high out-of-pocket expenses, which is poorly understood among service users.

"Well, what you see here and there is, that relatives plan the care provision of their loved ones according to what they can afford and not what they want." (Int. 13)

\section{Health professionals - urgently needed, but often not adequately qualified}

In addition to nursing professionals in various settings, numerous other stakeholders are involved in long-term care for IMV patients in the community sector. The respondents particularly thematized the relevance of general practitioners (GPs) and medical specialists, speech and language therapists, physiotherapists, occupational therapists, providers of medical supplies and pharmacists, especially with regards to their predominantly lacking qualifications and experiences. One expert illustrates the perceived fears among resident physicians of caring for long-term IMV patients.

"Partially, there is to fear your responsibility, to fear that you have to go there [to the patients, authors' note]. [...] of course, we all have a limited budget and time." (Int. 11)

The experts also criticize, that since GPs have limited global budgets, many of them seem to refuse the complex resource-intensive care of ventilated patients, and instead distribute the budget to a higher amount of less resourceintensive patients.

Overall, the respondents perceive deficits in primary, but also in specialist medical care for many IMV patients in community settings, especially in rural areas. As a result, they complain, critical but manageable situations may result in hasty and unnecessary hospital admissions, rather than in sound community-based medical and therapeutical interventions.

\section{Patient pathways - often end up in a deadlock}

A main objective of the research project was to explore typical pathways, long-term IMV patients take through the health system. Several interviewees reported that, in spite of recommendations in the guideline mentioned above (Windisch et al., 2017), patients do often not receive needs-based and graded interventions according to their complex demands, particularly with regards to stepping down from intensive care to post-intensive care units, systematically pursue individual potentials to rehabilitation and weaning, discharge management, monitoring and follow-up of the patient health state and care. Instead, they often seem to be transferred directly from the intensive care unit to community settings, where treatment, rehabilitation opportunities and weaning efforts are limited. Without appropriate therapy and rehabilitation, the experts point out, chances for ventilation weaning decline over time.

Moreover, the interviewees perceive that demands for informed and participatory decision-making during discharge and transition processes are disregarded by physicians and associated staff in charge. Rather, patients are guided to the next vacancy, regardless of the objective and perceived appropriateness of the care they receive. With such random pathways, particularly during transitions from acute to community care, quality criteria tend to fade into the background, the experts state: 
"The bed in the hospital has to get empty! And then it is random, a lucky strike, really like Russian roulette and depending on who's coming [which nursing service, author's note]. The hospitals then ask: 'Do I have a nice nurse? Oh, a nice looking one, I like her a lot. And if she tells me, they do a super standard and are certified or whatever. Great! I'll give her the patient."' (Int. 3)

A further challenge interviewees describe addresses the assurance of guideline-based regular follow-up that is not provided for every patient, due to limited capacities of expert centers and the non-binding nature of guideline recommendations. Some experts believe that many physicians and nurses in both, the hospital and the community sector, seem to be unaware that these follow-ups are pivotal to needs-based healthcare and ongoing review of weaning and rehabilitation potentials, that may be successful even after a long period of convalescence.

"The doctors and nurses have really no idea, where healthcare may lead to. I have the impression, that they [do] not really know that." (Int. 8)

As a result, patients may remain ventilator-dependent, and rehabilitation may not be fostered to its full potential for various reasons, such as ignorance or negligence. Accordingly, respondents conclude that the insufficient service availability and shortcomings in the management and monitoring of healthcare processes often play a more important role in determining patients' pathways and outcomes, than their specific situation and needs. They summarize, that patient pathways too often end up on a proverbial deadlock.

Cross-cutting challenges and needs for action - demand binding guideline specifications and integrated care

Most challenges and needs for action identified by the interviewees were highlighted in the context of the issues outlined above and without being explicitly asked. Their statements made clear that healthcare for IMV patients is challenging in terms of legal, political, economic and ethical issues. They repeatedly criticized the fact that the recommendations for long-term care for IMV-Patients within the existing guideline (Windisch et al., 2017) are not sufficiently binding:

"It's all recommendations, even from the expert society. [...] But recommendations are just recommendations and you can follow them, but you don't have to." (Int. 3)
Essentially, the development and multi-professional agreement of an evidence-based guideline is perceived as an important step in this long-neglected but growing health sector. But most experts highlight that without being legally binding, however, the guidelines' potential on user-oriented, professionally and ethically responsible healthcare remains untapped. Last but not least, they stress that the non-binding guideline character leads to an insufficient implementation that becomes apparent in the context of economic incentive systems, for example, for acute care hospitals, domestic nursing services and providers of supervised flat-sharing communities.

Interviewees illustrate these mechanisms by the example of hospitals' discharge: This process is perceived as often being driven by profit prospects, resulting in early and fast discharges and sometimes disregarding recommended procedures and actors who need to be involved to ensure smooth transitions. Additionally, potential monetary benefits nursing care services and providers of medical supplies can expect from patients with persistent ventilation in a relatively stable condition may result in inhibiting follow-up visits at specialized weaning centers. Such practices, resulting from insufficient guideline implementation and control mechanisms, would require sound regulation:

"And as long as that is not fixed by law, there will always be loopholes for these black sheep." (Int. 6)

To support prospective efforts to the development of evidence and needs-based healthcare, substantial investments in the expansion of weaning centers and early rehabilitation facilities are strongly encouraged. According to several respondents, such efforts are to date restrained by a poor understanding of the associated benefits at the political decision-making level. Closing this information gap, for example, by providing comprehensive health economic analyses, may, among other factors, contribute to initiating sound initiatives.

Additionally, a potential curative oversupply at the end of life is highlighted by the interviewees:

"Well, at least sometimes, we practice medicine beyond the medically reasonable level, sometimes even beyond the patient's will." (Int. 13)

Based on the interviewees' experiences, communication between clinicians, patients and families is often difficult, especially when a critical illness becomes chronic. Tracheostomy, prolonged mechanical ventilation, and other burdensome and resource-intensive interventions are often the results of missing comprehensive and participatory discourses about appropriate and realistic 
goals to healthcare for seriously ill people. In the interviewees' perception, these challenges also emerge from organizational routines and a lack of ethical skills among physicians, nurses and other professionals, inadequate legal knowledge, palliative skills and care structures. Consequently, IMV often seems to be continued, despite being recognized as futile. So, they call for an independent, central agency to manage, monitor and control health providers of long-term IMV patients and to establish standardized patient pathways. Also, a binding and legally protected regulation of care processes is desired. By adjusting and regulating remuneration and incentives for different services, respondents expect a shift from currently primary economic interests to more needs- and preference-based healthcare.

Some interviewees identify promising opportunities for improving the healthcare for IMV patients by establishing formalized collaborations following the logic of integrated care. Different partners (e.g., hospitals, rehabilitation facilities, GPs, nursing services) could be incorporated to develop patient-orientated, cross-linked healthcare approaches. Ideally, those collaborations should be built around expert ventilation and weaning centers with specialized expertise. This, they state, could only work, if the traditional fragmentation of the German health sectors in terms of quality assurance, development and economy is dissolved:

"Structures and processes can only be changed, if the split between institutional, I mean inpatient clinical treatment, and community care is broke down." (Int. 3)

Additionally, several experts suggest to establish inpatient transitional wards for unstable, chronically critically ill patients to identify and foster preventive and rehabilitative potential by adapting innovations from adjacent areas of care, such as specialist palliative home care. Interviewees also believe that the regular use of telehealth in community healthcare for IMV patients should be given more significant consideration.

\section{DISCUSSION}

The findings of this exploratory study present health professionals' perspectives on long-term care for IMV patients, typical pathways and existing challenges in four German regions. The results provide the first indepth empirical insights into an under-researched and largely nontransparent area of healthcare for a highly vulnerable patient group in Germany, confirming already existing anecdotal reports on existing challenges. Most interviewees in this study characterized specialized healthcare for long-term IMV patients as deficient with regards to structures, processes and patient pathways.
Surprisingly, the respondents were very open and eager to share their experiences, which arguably point to the pressing problems, discussed in more detail below based on the principles of needs-based health system design, continuity and integration of individual case management.

\section{Fragmented and insufficient structure and service development}

Interviewees highlight regional disparities and lacking capacities of specialized acute care and rehabilitation facilities, community nursing services, GPs, medical specialists and therapists in healthcare for long-term IMV patients especially in rural regions. These findings are supported by a spatial analysis of specialized services for long-term IMV patients within the VELA-Regio study (Stark et al., 2016) and are also argued internationally (e.g., Laub et al., 2004). Reasons for this were detected in the inhomogeneous, non-regulated and hypothetically interest-driven service developments during the past decades.

Deficient health structures and a lack of qualified professionals are questioning the appropriateness of healthcare and might indicate on oversupply, undersupply and inappropriate healthcare on the one hand. On the other, the experts add, appropriateness and needs-orientation, especially of care arrangements in home care and flat-sharing community settings, are frequently put into question. Not only because of lacking and often poorly trained professionals, but also due to perceived and experienced challenges regarding patient safety, participation, rehabilitation and quality of life. The underlying causes identified lie in economic provider interests, constraints resulting from regulations inherent to the German health and social system (e.g., G-DRGbased remuneration of inpatient care, funding of nursing home accommodation) and lacking control mechanisms (also see DIGAB, 2017).

Little it is known about the extent of quality and safety problems in typically hard-to-control home care settings (inter-)nationally (Masotti et al., 2010; Doran et al., 2014). External quality audits from the German Medical Service of the Health Funds suggest that the quality and patient safety in this setting is not in good shape (MDS, 2017). However, specific (inter-)national data on home care for long-term IMV patients and other technologydependent patients are almost entirely lacking (Ewers \& Lehmann, 2018). At the same time, it is widely acknowledged that high-quality care for long-term IMV patients requires high professional qualification, quality and safety standards (Baxter et al., 2018). Specific training on intensive home care or home mechanical ventilation is recommended, for example, by the German guideline on long-term IMV (Windisch et al., 2017) for 
nursing staff and other professionals. To what extent the German professionals involved in specialized care for the patient group are qualified accordingly, is yet widely unknown. As opposed to Germany, where nursing providers are responsible to ensure adequate long-term care of IMV patients, these tasks are primarily conducted by informal caregivers and assistants in various countries is (Swedberg et al., 2015; Dale et al., 2018). In contrast, the role of family caregivers and nursing assistants in Germany is often marginalized (Lademann, 2007; Schaepe \& Ewers, 2018). Few studies on the role of informal caregivers in Germany show that task-sharing with nurses and limited informal caregiver expertise often seem to be insufficiently reflected (ibid.). Given the reported shortage of qualified nursing staff, it seems to be overdue to step up discussions on the systematic integration of informal and assistant caregivers based on international practice and experiences and by taking into account the impact of nursing task shifting on care processes seems to be overdue. Informal caregivers should be supported with participatory professional collaboration, purposeful fostering of their expertise (Swedberg et al., 2015) and protection from excessive demands (Dale et al., 2018). International conceptual approaches providing structured training and education for informal caregivers in charge of long-term care of IMV patients may provide orientation (Stark \& Ewers, submitted).

\section{Random processes and patient pathways}

As the results show, professionals are familiar with patient pathways, allocation processes and responsibilities formalized in the relevant German guideline (Windisch et al., 2017), but criticize that they are not sufficiently binding. Accordingly, patient pathways are evaluated too often as being individual results of experiencebased, informal networking, and left to chance. Instead, the commitment of single health providers seems to determine whether long-term IMV patients receive appropriate healthcare at the right time and in the right setting, and if quality and safety aspects are taken into account.

But in fact, long-term care goal setting and provision for IMV patients is affected by individual disease trajectories and various ethical challenges (Dybwik et al., 2012; Jox et al., 2012). For example, a slow recovery process (e.g., from chronic critical illness) may impact weaning efforts, or a progressive respiratory failure may require advance care planning and palliative care (Nelißen et al., 2018). Thus, care planning and management for these patients should not solely depend on personal commitment but rather consider individual, social and religious needs as well as quality of life besides the common aspect of (long-term) survival (Geiseler \& Schönhofer, 2016). From the interviewees' point of view, these multifaceted and differing complex needs, which require adjusted and graded interventions, do not seem to be fully recognized by professionals and leads to a potential waste of potentials for reasonable interventions (ibid.). This especially applies to discharge from inpatient settings, rehabilitation and weaning attempts, ongoing health monitoring ad follow-up. Respondents recognize nontransparent and secondary interests of stakeholders (e.g., care providers) as significant influences on these shortcomings. Moreover, some interviewees believe that the perceived increase in the prevalence of long-term IMV in Germany is - besides epidemiological/demographic changes and technological advances in healthcare - particularly accelerated by financial incentives, poor communication and qualification deficits especially concerning ethical aspects and palliative care (also see Schönhofer et al., 2016; DIGAB, 2017).

Due to these procedural challenges combined with insufficient health structures, control mechanisms, quality and safety standards, appropriate care arrangements that carefully take into account individual needs, rehabilitation and weaning potentials may not be established for each long-term IMV patient in Germany. As some respondents state, patient pathways may end up on a deadlock. Against this background, an urgent need to improve the healthcare for long-term IMV patients in Germany becomes apparent. Approaches to integrating the various sectors and professions, with particular attention on establishing continuing and needs-based processes and pathways should - as some interviewees also emphasize - be taken into account. To that effect, the interviewed professionals desire a binding and legal regulation of healthcare processes, that is also called for by different patient organizations, professional and expert associations (DIGAB, 2017; Windisch et al., 2019).

\section{Need for integrated, needs-based health system design}

Several participants repeatedly highlighted that depending on their situation, IMV patients or other technologydependent patient groups require a wide range of specialized health structures and services, ranging from acute care, rehabilitation and long-term to palliative care and involving various providers. Unfortunately, the well-known problems of the German health system, such as the strict separation of the inpatient and community sector (Advisory Council, 2014) provoke interface problems and severe consequences for the healthcare for long-term IMV patients. The German Advisory Council on the Assessment of Developments in the Health System repeatedly called for overcoming this health system 
fragmentation, the lack of transparency, and regulative restrictions on inter-professional collaboration and care continuity (ibid.). So far, with limited success.

The interviewees' suggestions for German approaches that may contribute to improved healthcare for longterm IMV patients should ideally contain tertiaryexpert-center based concepts at ventilation and weaning centers to continually provide specialized IMV expertise to professionals, patients and (informal) caregivers. Approaches should foster cross-sectoral collaboration and formal cooperation between organizations and professions, adopt telehealth interventions and should be supervised by an independent, central monitoring agency. Particular emphasis should be paid to evidence-informed concepts that enable graded, needs-based patient pathways through the health system. Inpatient expert center and rehabilitation capacities should be expanded to foster preventive and rehabilitative potentials of long-term IMV patients (DIGAB, 2017). In addition, palliative and endof-life care expertise and structures should be expanded to adequately respond to patient needs and preferences, even if this leads to withdrawal or withholding treatment (Jox et al., 2012; Geiseler \& Schönhofer, 2016).

These demands correspond to the principles inherent to healthcare integration (e.g., WHO, 2015), that has the potential to enhance healthcare quality and outcomes, especially for vulnerable patient groups with complex care needs with continuing, needs-based graded, interprofessional and cross-sectoral approaches (WHO, 2015; Baxter et al., 2018). As opposed to Germany, concepts aiming at integrating healthcare for long-term IMV patients and similar patient groups have already been implemented and utilized in countries like Canada, the United States or Spain. And although evidence on the feasibility and benefits of such concepts is limited, they seem to positively affect (patient-related) outcomes, care coordination, healthcare utilization or costs (Stark \& Ewers, submitted). They should, therefore, be carefully considered and adopted for tackling existing challenges and further development of healthcare for long-term IMV patients and similar patient groups in Germany. Feasibility, effectiveness and efficiency of adequate concepts should be regionally piloted, scientifically evaluated and, if successful, implemented as comprehensively. Interestingly, most of the already existing concepts adopted a multi-professional approach, comprising at least clinical, home and social services, with advanced nursing professionals in charge of care coordination (Stark \& Ewers, submitted). Following existing guidance, integrated approaches should involve various institutions and health professions from different sectors. This, in turn, requires a coordinated, crosssectoral financing model legitimized by social law, as well as close coordination between different payers - for example, the German statutory health and the long-term care insurance. The German Code of Social Law for the statutory health insurance already provides corresponding legal opportunities for cross-sectoral collaboration and financing (e.g., § 140a Social Code of Law V) that should be carefully considered.

\section{Limitations}

The four regions studied cover a wide range of social, demographic and infrastructural conditions in Germany. The study included the metropolis of Berlin with a high density of specialized care facilities, urban (Schwerin, Tübingen) and rural regions (Hof) of East and West Germany (Berlin, Mecklenburg-Western Pomerania, Baden-Wuerttemberg, Bavaria). Based on their characteristics, they can be considered exemplary for other German regions (Stark et al., 2016). However, generalizability and transferability of the study results are limited, since healthcare in Germany is highly regulated and governed at a federal state level, and previous studies revealed that regional disparities occur even in homogeneous health systems, such as Sweden (Laub et al., 2004). Limitations of the study also include a potential selection bias. In order to obtain different professional perspectives, we interviewed experts with a wide range of responsibilities, institutional and professional affiliations from different sectors and settings in each region. But due to differing regional health structures and limited research resources, the number of interviews per region was not determined by data saturation. Thus, certain regional perspectives may not have been taken into account.

Nevertheless, the results provide orientation in the crosssectoral field of healthcare for long-term IMV patients with complex technology-intensive support needs, which has just recently gained attention at a health policy level. The results reveal knowledge gaps that should be addressed by future research.

\section{CONCLUSION}

The results of this exploratory study point to deficits in specialized healthcare to long-term IMV patients in Germany. Notwithstanding the limited number of study participants and the contextual dependency of findings, several challenges and needs for action become apparent. Existing health structures and services for these patients have been developed without clear concepts and mainly in the absence of scientific evidence. Much of the processes seem to occur randomly and are poorly regulated at the policy level. Hence, the health system does not adequately address the specific needs of IMV patients. 
More scientific evidence is required to reach build basics for rigorous, viable plans and decisions to further develop the field. This applies to quantitative epidemiological indicators and information on health outcomes. Moreover, long-term IMV should also be evaluated against patient-reported and system-level outcomes, such as health-related quality of life, hospitalization needs, resource utilization, or the role of caregivers (MacIntyre et al., 2016). Finally, more qualitative-empirical needs assessments are required, especially from the user $\square \mathrm{s}$ perspective (Schaepe \& Ewers, 2018; Geiseler \& Schönhofer, 2016).

To prospectively achieve a more patient-oriented structural, service, process and, quality development of specialized healthcare, which takes into account the demands on care continuity and integration of various professionals and sectors involved, data-informed strategies and intensified scientific engagement is crucial. More attention should be paid to research and development in the area of healthcare for severely chronically ill and technology-dependent patients in Germany beyond the scope of single sectors, organizations or professions. The particular challenges to be addressed include: developing evidence-based knowledge on patients' needs, developing and verifying quality and safety standards and developing integrated, needs-based models of care.

\section{ACKNOWLEDGMENT}

We thank all interview partners for their contribution to the project VELA-Regio.

\section{ETHICAL APPROVAL}

The health services research project VELA-Regio did not need formal ethical approval, as it did not involve any direct patient contact (Charité, 2019).

\section{CONFLICT OF INTEREST}

The project VELA-Regio was conducted with support from the AOK federal association (AOK Bundesverband). The authors report no conflict of interest.

\section{References}

Advisory Council - Advisory Council on the Assessment of Developments in the Health System. Needs-based Healthcare (2014). Opportunities for Rural Regions and Selected Health Sectors, Report 2014, Abridged Version. https://www.svrgesundheit.de/fileadmin/user_upload/Gutachten/2014/SVRGutachten_2014_Kurzfassung_engl.pdf [last access: 22.12.2019].

Ambrosino, N. \& Vitacca, M. (2018). The patient needing prolonged mechanical ventilation: a narrative review. Multidiscip Respir Med 13, Art. 6.

Baxter, S., Johnson, M., Chambers, D., Sutton, A., Goyder, E. \& Booth, A. (2018). The effects of integrated care: a systematic review of UK and international evidence. BMC Health Serv Res 18(1), Art. 350.

Bundessozialgericht (1999). Urteil B 3 KR 4/98 R. vom 28. Januar 1999. https://lexetius.com/1999,1453 [last access: 22.12.2019]

Charité - Universitätsmedizin Berlin (2019). Neubekanntmachung der Satzung der Ethikkommission der Medizinischen Fakultät in der Fassung vom 22. März 2019. Amtliches Mitteilungsblatt der Charité Nr. 230, 27.03.2019.

Dale, C. M., King, J., Nonoyama, M., Carbone, S., McKim, D., Road, J., Rose, L. on behalf CANuVENT group (2018). Transitions to Home Mechanical Ventilation: The Experiences of Canadian Ventilator-Assisted Adults and Their Family Caregivers. Ann Am Thorac Soc 15(3), 357-364.

Destatis - Statistisches Bundesamt (2018). Pflegestatistik: Pflege im Rahmen der Pflegeversicherung - Deutschlandergebnisse, 2017. Wiesbaden: Statistisches Bundesamt.

DIGAB - Deutsche Interdisziplinäre Gesellschaft für Außerklinische Beatmung (2017). Tracheostomy home care of patients after long-term ventilation on the ICU - a position paper. Dtsch Med Wochenschr 142(12), 909-911.
Doran, D., Blais, R., Baker, G. R., Harrison, M. B., Lang, A., Macdonald, M., McShane, J. \& Killackey T. (2014). The safety at home study: An evidence base for policy and practice change. Healthc Q 17(3), 42-47.

Dybwik, K., Nielson, E. W. \& Brinchmann, B. S (2012). Ethical challenges in home mechanical ventilation: a secondary analysis. Nurs Ethics 19(2), 233-244.

Ewers, M. \& Lehmann, Y. (2018). Langzeitpflege für Pflegebedürftige mit therapeutisch-technischem Unterstützungsbedarf. In: Szepan, N. M. \& Wagner, F. (Eds.). Agenda Pflege 2021. Berlin: KomPart, pp. $135-153$

Geiseler, J. \& Schönhofer, B. (2016). Ethics and palliative medicine in intensive care and ventilation. Pneumologie 13(2), 104-112.

Geisewall, K., Håkansson, S., Oddby, E., Ek, M. E. \& Jacobsson, J. G. (2015). National respiration center support patients with tracheostomy tubes. Outpatient clinic for respiratory support in the home. Lakartidningen 112, pii DD3Y.

Jox, R. J., Schaider, A., Marckmann, G. \& Borasio, G. D. (2012). Medical futility at the end of life: the perspectives of intensive care and palliative care clinicians. J Med Ethics 38(9), 540-545.

Lademann, J. (2007). Intensivstation zu Hause. Pflegende Angehörige in High-Tech Home Care. Bern: Huber.

Laub, M., Berg, S. \& Midgren, B. (2004). Home mechanical ventilation in Sweden - inequalities within a homogenous healthcare system. Respir Med 98(1), 38-42.

Lehmacher-Dubberke, C. (2016). Krankenpflege auf Rädern. G+G Gesundheit und Gesellschaft 19(3), 30-33

Lehmann, Y., Stark, S. \& Ewers, M. (2016a). Versorgung invasiv langzeitbeatmeter Patienten unter regionalen Gesichtspunkten VELA Regio. Teil 1: Kommentierte Bibliografie. Working Paper 16-01 der Unit Gesundheitswissenschaften und ihre Didaktik. 
Charité - Universitätsmedizin Berlin, http://dx.doi.org/10.17169/ refubium-1916.

Lehmann, Y., Stark, S. \& Ewers, M. (2016b). Versorgung invasiv langzeitbeatmeter Patienten unter regionalen Gesichtspunkten VELA-Regio. Teil 3: Strukturen und Prozesse aus Akteurssicht. Working Paper 16-03 der Unit Gesundheitswissenschaften und ihre Didaktik. Charité - Universitätsmedizin Berlin, http://dx.doi. org/10.17169/refubium-1918.

MacIntyre, E. J., Asadi, L., McKim, D. A. \& Bagshaw, S. M. (2016). Clinical outcomes associated with home mechanical ventilation: a systematic review. Can Respir J, Art. 6547180.

Masotti, P., McColl, M. A. \& Green, M. (2010). Adverse events experienced by homecare patients: A scoping review of the literature. Int J Qual in Healthcare 22(2), 115-125.

MDS - Medizinischer Dienst des Spitzenverbandes Bund der Krankenkassen (2017). 5. Pflege-Qualitätsbericht. Essen: MDS.

Meuser, M. \& Nagel, U. (2009). Experteninterview - konzeptionelle Grundlagen und methodische Anlage. In: Pickel, S., Pickel, G., Lauth, H. J. \& Jahn, D. (Eds.): Methoden der vergleichenden Politik- und Sozialwissenschaft. Wiesbaden: VS Verlag für Sozialwissenschaften, pp. 465-479.

Nasiłowski, J., Wachulski, M., Trznadel, W., Andrzejewski, W., Migdał, M., Drozd, W., Pytel, A., Suchanke, R., CzajkowskaMalinowska, M., Majszyk, T., Szkulmowski, Z. \& Chazan, R. (2015). The evolution of home mechanical ventilation in Poland between 2000 and 2010. Respir Care 60(4), 577-85.

Nelißen, V., Metzing, S. \& Schnepp, W. (2018). Experiences of patients with invasive and non-invasive home mechanical ventilation - a systematic review of qualitative research. Pneumologie 72(7), 514-522.

Povitz, M., Rose, L., Shariff, S. Z., Leonard, S., Welk, B., Jenkyn, K. B., Leasa, D. J. \& Gershon, A. S. (2018). Home Mechanical Ventilation: A 12-Year Population-Based Retrospective Cohort Study. Respir Care 63(4), 380-387.

Rose, L., McKim, D. A., Katz, S. L., Leasa, D., Nonoyama, M., Pedersen, C., Goldstein, R. S., Road, J. D. on behalf of the CANuVENT Group (2015). Home mechanical ventilation in Canada: a national survey. Respir Care 60(5), 695-704.

Sahetya, S., Allgood, S., Gay, P. C. \& Lechtzin, N. (2016). Long-Term Mechanical Ventilation. Clin Chest Med 37(4), 753-763.

Schaepe, C. \& Ewers, M. (2018). "I see myself as part of the team" family caregivers' contribution to safety in advanced home care. BMC Nursing 17, Art. 40.

Schönhofer, B., Geiseler, J., Jany B et al. on behalf of WeanNet-StudyGroup (2016). WeanNet: The network of weaning units of the DGP - results to epidemiology an outcome in patients with prolonged weaning. Dtsch Med Wochenschr 141(18), e166-e172.

Simonds, A. K. (2016). Home mechanical ventilation: an overview. Ann Am Thorac Soc 13(11), 2035-2044.

Social Code of Law V - Sozialgesetzbuch (SGB), Artikel 1 des Gesetzes vom 20.12.1988, Fünftes Buch, BGB1 I S. 2477, https:// www.gesetze-im-internet.de/sgb_5/.
Stark, S., Lehmann, Y. \& Ewers, M. (2016). Versorgung invasiv langzeitbeatmeter Patienten unter regionalen Gesichtspunkten - VELA-Regio. Teil 2: Bedarf und Strukturen. Working Paper 16-02 der Unit Gesundheitswissenschaften und ihre Didaktik. Charité - Universitätsmedizin Berlin, http://dx.doi.org/10.17169/ refubium-1917.

Stark, S., Lehmann, Y. \& Ewers, M. (2019). Intensivversorgung tracheotomierter Patienten mit und ohne Beatmung Bedarfsgerechtigkeit regionaler Angebote. Working Paper 19-01 der Unit Gesundheitswissenschaften und ihre Didaktik. Charité - Universitätsmedizin Berlin, http://dx.doi.org/10.17169/ refubium-2339.

Stark, S. \& Ewers, M. (submitted). Long-term care for tracheotomized patients with or without invasive ventilation. Lessons learned from a scoping review of international concepts. Provided for: Int $\mathrm{J}$ Integr Care.

Swedberg, L., Michélsen, H., Chiriac, E. H. \& Hylander, I. (2015). On-the-job training makes the difference: healthcare assistants perceived competence and responsibility in the care of patients with home mechanical ventilation. Scand J Caring Sci 29(2), 369-372.

WHO - World Health Organization (2015). WHO global strategy on people-centred and integrated health services. Geneva: WHO.

Windisch, W., Dreher, M., Geiseler, J et al. on behalf Leitliniengruppe „Nichtinvasive und invasive Beatmung als Therapie der chronischen respiratorischen Insuffizienz“ (2017). Guidelines for non-invasive and invasive home mechanical ventilation for treatment of chronic respiratory failure - update 2017. Pneumologie 71(11), 722-795.

Windisch, W., Callegari, J. \& Karagiannidis, C (2019). Home mechanical ventilation in Germany. Dtsch Med Wochenschr 144(11), 743-747. 